vertaald moet worden: 'nuttig' lijkt iets meer een positieve connotatie te hebben dan 'bruikbaar' - dat laatste woord staat meer symmetrie toe in het analyseren van kennisgebruik voor zowel nutte en onnutte doelen. Evenzeer kunnen we echter aan Joel Mokyr vragen of in het Engels de term 'usable knowledge' niet beter de beoogde connotatie benadert dan 'useful knowledge.'

$\mathrm{Al}$ met al is Mokyrs boek de eerste studie van economische ontwikkeling die een constructivistische interpretatie van kennis en techniek echt serieus neemt en integreert in de eigen theorievorming: 'Science and technology, as the constructivist school insists, are social processes. This approach is not as remote from the thinking of economists as they believe. ${ }^{\text {I9 }}$ (287)

Karel Davids

\title{
Aan de oever van de Rubicon
}

\section{Kennis, markt en vooruitgang in Mokyrs The Gifts of Athena}

The Gifts of Athena is een voor economisch-historici uitzonderlijk boek. Waagde Joel Mokyr zich in The Lever of Riches zich al unverfroren op een terrein - technologische creativiteit - dat de meeste van zijn vakbroeders het liefst luchtdicht opgeborgen in een black box laten zitten, in The Gifts of Athena gaat hij weer enthousiast een stap verder. ${ }^{20} \mathrm{Hij}$ onderzoekt nu de rol van kennis in economische groei in het algemeen.

Anders dan in The Lever of Riches, dat de relatie tussen technologische creativiteit en economische vooruitgang over een breed front door de hele menselijke geschiedenis heen bestrijkt, ligt in dit nieuwe boek de nadruk meer op theorie-ontwikkeling en analytische verfijning dan op sectoriële variatie of geografische en chronologische reikwijdte. De kernvraag van The Gifts of Athena luidt, hoe nieuwe kennis heeft bijgedragen tot de huidige welvaart en materiële cultuur. Daarbij kijkt Mokyr vooral naar de ontwikkeling van de industriële techniek, met name in Engeland, Frankrijk en Duitsland, vanaf de achttiende eeuw tot heden. $\mathrm{Na}$ in het eerste hoofdstuk van zijn boek een algemene theorie over de ontwikkeling van 'nuttige' kennis te hebben geïntroduceerd en toegelicht, analyseert hij aan de hand van deze theorie in hoofdstuk 2 en 3 het ontstaan van de Industriële Revolutie en latere golven van tech-

19. 'They' is hier dubbelzinnig: het kan zowel naar de constructivisten als naar de economen verwijzen. Wat mij betreft had Mokyr 'both' mogen gebruiken.

20. Joel Mokyr, The Lever of Riches. Technological creativity and economic progress (New York/ Oxford I990). 
nische vernieuwing alsmede de gevolgen daarvan voor de groei van productiviteit, ontleedt daarna het verband tussen kennisontwikkeling en veranderingen in bedrijfsorganisatie, gezondheid, hygiëne en huishoudelijk werk (hoofdstuk 4 en 5) en rondt het betoog af met een theoretische en historische beschouwing over de politiek-institutionele context waarbinnen de groei en verspreiding van 'nuttige' kennis kan plaatsvinden (hoofdstuk 6 en 7). De voornaamste concepten en argumenten die Mokyr in The Gifts of Athena ontwikkelt, worden al samengevat in de stukken van Bijker, Dolfsma en Van Driel. Hun commentaar richt zich voornamelijk op de economische en epistemologische facetten van het boek. Mijn bijdrage aan het discussiedossier zal zich concentreren op de historische en politiek-institutionele aspecten.

De intellectuele spankracht die uit dit boek spreekt is fenomenaal. Er zitten zoveel uitdagende ideeën, prikkelende stellingen en fraaie vondsten in The Gifts of Athena, dat historici, economen en sociologen (en niet te vergeten, politici) er jaren mee vooruit kunnen. Als er één boek is dat het debat over de 'kenniseconomie' een kwaliteitsimpuls geeft, dan is het wel The Gifts of Athena. De theorie over 'propositionele' en 'prescriptieve' kennis en de relatie tussen deze twee sferen in loop van de tijd, die Mokyr in hoofdstuk I uiteenzet, of zijn analyse van het hoe en waarom van weerstand tegen vernieuwingen (en het verband met Cardwell's Law) in hoofdstuk 6 zal stellig een golf van nieuw onderzoek uitlokken. Naast zijn vernieuwende aanpak van problemen op 'macro-niveau', zal ook Mokyrs originele en inventieve benadering van vraagstukken op 'micro-niveau', zoals de ratio van het fabrieksysteem of de oplossing van het 'Ruth Schwartz Cowan-probleem', vakgenoten en anderen inspireren om nieuwe vragen te stellen, nieuwe antwoorden te bedenken, nieuwe bronnen aan te boren of een totaal andere these te presenteren. ${ }^{2 \mathrm{I}}$ Kortom, The Gifts of Athena is een prestatie van Schumpeteriaanse allure.

Hoe grensverleggend het boek ook is, ik kan mij niet aan de indruk onttrekken dat de schrijver halt houdt op een punt waar het betoog nog radicaler zou kunnen worden. Hij is aan de oever van de Rubicon gekomen, maar steekt hem niet over. Hoe ver hij het neoklassieke model intussen ook achter zich heeft gelaten, ${ }^{22}$ hij lijkt zijn baanbrekende analyses (nog) niet tot de uiter-

21. Onder Cardwell's Law, genoemd naar de techniekhistoricus D.S.L.Cardwell, verstaat Mokyr de empirische wetmatigheid dat 'no nation has been (technologically) very creative for more than an historically short period' (The Lever of Riches, 207). Met het 'Ruth Schwartz Cowan-probleem' bedoelt hij de paradox - gesignaleerd in het boek More Work for Mother (New York 1983) van de gelijknamige auteur - dat 'homemakers worked longer hours in their homes in the century after I870, despite the growing mechanization of household activities' (Mokyr, The Gifts of Athena, 198-199).

22. Vergelijk de analyse van de ontwikkeling van Mokyrs werk sinds de verschijning van zijn eerste boek, Industrialization in the Low Countries (New Haven I976) in J.W. Drukker, De revolutie die in haar eigen staart beet. Hoe de economische geschiedenis onze ideeën over economische groei veranderde (Utrecht 2003) 270-27I. 
ste consequentie door te willen voeren. Het volgende commentaar is als een uitnodiging aan de auteur bedoeld, om toe te lichten waarom hij op dit punt stopt, dan wel om alsnog de oversteek te maken.

In zijn analyse gaat Mokyr van tenminste drie vooronderstellingen uit. Een eerste vooronderstelling is, dat 'technology makes people more powerful in exploiting nature, but how and for what purpose they do so remains indeterminate' (297). ${ }^{23}$ Techniek opent deuren, 'it does not force society to walk through them' (I62). Technische ontwikkeling op zich is voor Mokyr identiek aan technische vooruitgang. De termen zijn in het boek in feite onderling verwisselbaar. Als er misbruik van techniek wordt gemaakt, zo luidt de volgende vooronderstelling, dan ligt dat aan de omstandigheid dat - 'the capacity of humans for intolerance, stupidity, and selfishness has not declined as their technological power has increased' (297). Verzet tegen technologische verandering, zo zegt een derde fundamentele veronderstelling, is echter op zich geen bewijs van irrationeel gedrag; integendeel, 'technological inertia was usually the outcome of rational behavior by utility-maximizing individuals' (232-232).

De vraag rijst, of deze vooronderstellingen onderling verenigbaar of empirisch houdbaar zijn. Is technische ontwikkeling op zich werkelijk 'progressief, of op zijn minst neutraal? Het is waar dat techniek door mensen wordt gemaakt en uit zichzelf niets 'doet', maar suggereert Mokyrs formulering toch niet een te grote onafhankelijkheid en waardevrijheid? In de eerste hoofdstukken van zijn boek betoogt de auteur immers, a) dat elke techniek - oftewel elk element in het domein van 'prescriptieve kennis' $(\lambda)$ - berust op 'a known set of natural phenomena and regularities that support it' in het domein van 'propositionele kennis' $(\Omega)$ (I3-I4), b) dat $\Omega$-kennis niet per se waar is (althans alleen elementen bevat die nu als 'waar' worden beschouwd) (6) en c) dat de interactie tussen deze twee domeinen vanaf de 'Industriële Verlichting' sterk toenam, waarbij ook steeds meer feedback plaatsvond van $\lambda$ naar $\Omega$ (20-2I, 54-56). Daaruit valt af te leiden dat technologie ( $\lambda$-kennis) 'vervuild' kan raken door 'niet-ware' kennis in het $\Omega$-domein, terwijl het $\Omega$ domein weer gevoed kan worden met 'niet-ware' kennis uit de sfeer van de techniek. Het zou natuurlijk kunnen zijn dat het $\Omega$-domein sinds de 'Industriële Verlichting' geen 'onware' kennis meer bevat - de voorbeelden van 'pieces of $\Omega$ that are no longer accepted' die Mokyr op bladzijde 6 noemt, namelijk de humoraalpathologie en de phlogistontheorie, dateren beide van vóór I80o! -, maar dat strookt niet met de feiten. De 'kennis'-ontwikkeling in de periode sinds de Verlichting heeft de mensheid per slot van rekening onder meer de frenologie, de rassenleer en de eugenetica bezorgd, die aanvankelijk in brede kring werden aanvaard maar inmiddels tot dezelfde status zijn gedegradeerd als de humoraalpathologie en de phlogistontheorie. Even-

23. De nummers tussen haakjes verwijzen naar de bladzijden in The Gifts of Athena. 
als deze laatste staaltjes van $\Omega$-kennis zijn ze de basis geweest voor allerlei vormen van manipulatie in het $\lambda$-domein, maar dan met consequenties die voor grote groepen mensen onvergelijkelijk veel negatiever zijn geweest. ${ }^{24}$

De mogelijk schadelijke neveneffecten die de groei van $\Omega$ en $\lambda$-kennis (en hun toenemende interactie sedert de Industriële Verlichting) voor welvaart en welzijn kunnen hebben, zijn niet zonder belang voor de analyse van de politiek-institutionele context van kennisontwikkeling. Mokyr is van mening dat, ook al zijn niet alle 'free-enterprise economies [...] necessarily technologically creative', ook al is 'some role for a government in the direction of technological progress warranted' en ook al zijn 'not all command economies [...] technologically stagnant', technische vooruitgang niettemin 'a better chance in the long run' heeft in 'free, self-organizing market societies than in command economies' (223). De sleutel tot 'technological progress' is in zijn visie namelijk 'overcoming the built-in resistance' tegen vernieuwing (224). Hoezeer Mokyr ook (meer dan menig collega) oog heeft voor het feit dat aanvaarding van vernieuwingen niet alleen een economisch maar ook een politiek fenomeen is (220-22I, 23I), het grootste deel van hoofdstuk 6 over 'The political economy of knowledge' is toch gericht op het analyseren van het hoe en waarom van weerstand tegen de invoering van nieuwe kennis (232-282). Als de tweede vooronderstelling van de auteur klopt, is er echter geen reden om weerstand tegen technische vernieuwing problematischer te vinden dan aanvaarding van nieuwe kennis in de $\Omega$ en $\lambda$-sfeer. Wanneer aanvaarding van nieuwe kennis kan voortkomen uit het onverminderde vermogen van mensen 'for intolerance, stupidity, and selfishness' (ook na de Verlichting), terwijl weerstand 'usually' als het resultaat van 'rational behavior by utility-maximizing individuals' kan worden beschouwd, is er dan zelfs niet aanleiding om het hoe en waarom van aanvaarding nader te analyseren en de vraag te stellen of de vrije markt inderdaad de best mogelijke context biedt voor technische vooruitgang? Zeker, afgezien van Fidel Castro en Kim Jung Il zal niemand nog beweren dat een bevelseconomie de mensheid naar het paradijs voert (in plaats van naar het kerkhof). Maar kan tussen markt en coördinatie niet ergens een optimale mix gevonden worden?

Gelet op de technische ontwikkeling van de afgelopen decennia, dringt zich ten slotte de vraag op, in hoeverre de creatie en selectie van grensverleggende nieuwe technieken ook in de westerse geïndustrialiseerde wereld eigenlijk nog wel plaatsvindt - of zelfs kan plaatsvinden - in een context waarbij het primaat geheel bij de markt ligt en de overheid hoogstens slechts een

24. Voor een minder bekend voorbeeld daarvan (de toepassing van eugenetica in de Scandinavische landen tussen de jaren twintig en de jaren vijftig van de zoe eeuw), zie Gunnar Broberg en Nils Rohl-Hansen, Eugenics and the Welfare State. Sterilization policy in Denmark, Sweden, Norway and Finland (East Lansing I996). 
ondersteunende rol speelt. Macro-inventies die in hoge mate bepalend zijn voor de huidige welvaart en materiële cultuur, zoals het internet of plaatsbepaling met GPS, zijn immers voortgekomen uit het militaire apparaat. ${ }^{25} \mathrm{Ze} \mathrm{zijn}$ oorspronkelijk als instrumenten in het kader van de wapenwedloop en ruimtewedloop tijdens de Koude Oorlog ontwikkeld. E-commerce was niet de eerste toepassing waar de top brass aan dacht. De markt verscheen pas later in beeld.

The Gifts of Athena is een briljant boek. In het bovenstaande commentaar heb ik aangegeven, dat het niet alleen vol zit met allerlei schitterende ideeën en uitdagende inzichten over technische en economische ontwikkeling, maar impliciet ook boeiende vragen oproept over de neveneffecten van technische vooruitgang en de wenselijkheid van het primaat van de vrije markteconomie. De auteur neemt, naar mijn inschatting, bij zijn analyse op deze punten een meer terughoudende positie in dan zijn eigen uitgangspunten en het empirische materiaal mogelijk maken. Hij heeft zijn tenten opgeslagen aan de oever van de Rubicon. Zal hij hem oversteken?

Joel Mokyr

\section{Kennis, vooruitgang, en verandering in de economische geschiedenis}

The Gifts of Athena is gebaseerd op het idee dat moderne economische groei, die omstreeks I80o op gang kwam, steunde op de groei van nuttige kennis. Wat was nu precies 'nuttig' aan die kennis? Wat ik bedoelde was meer een 'kennis der natuur' - het soort kennis van natuurlijke verschijnselen en regelmatigheden waar technieken, die de natuur exploiteren, op kunnen berusten. Eigenlijk is het concept ontleend aan het werk van Simon Kuznets. Het is interessant te constateren dat in de jaren vijftig Kuznets de term useful knowledge (nuttige kennis) nog afwisselde met de term testable knowledge (toetsbare kennis), die hij kennelijk als evenredig beschouwde. In zijn Nobelprijsrede van I97I komt het tweede concept niet meer voor. ${ }^{26}$ Dat is ook wel beter: toetsbare kennis lijkt me een riskant concept: toetsbaar door wie, en op basis van welke maatstaven $?^{27}$

Het onderscheid tussen propositionele kennis en voorschrijvende kennis is de grondslag van mijn theorie. Maar waar misschien niet genoeg nadruk op is gelegd, is het evolutionaire karakter van de kennisverandering, namelijk dat

25. Zie over de ontwikkeling van het internet: Janet Abbate, Inventing the Internet (Cambridge, Mass. I999).

26. Zie Simon Kuznets, Economic Growth and Structure (New York I965) en idem, Modern Economic Growth: Findings and Reflections. Nobel Prize Lecture (Singapore I97I); ook op http://www.nobel.se/economics/laureates/I97I/kuznets-lecture.html. [I5 februari 2004] 